Daniela Marčok

Univerzitet u Novom Sadu

Filozofski fakultet

Odsek za slovakistiku

danielamarcokova@ff.uns.ac.rs
УДК 811.162.4:371(497.1)"192/194"

https://doi.org/10.18485/slavistika.2019.23.2.13

Прегледни рад

примљено 04.03.2019.

прихваћено за штампу 10.10.2019.

\title{
OBRAZOVANJE U KONTEKSTU SLOVAČKO-SRPSKIH ODNOSA U OSNOVNOJ ŠKOLI SA SLOVAČKIM NASTAVNIM JEZIKOM U KISAČU U KRALJEVINI SHS*
}

Posle Prvog svetskog rata i nastanka nove države Kraljevine SHS, škole postaju državne, a učitelji državni činovnici. Iako zakon nalaže da jezik nastave u svakoj školi mora biti maternji jezik njenih učenika, zakon takođe obavezuje da se nastava nekih predmeta vrši na državnom jeziku. Zadatak malobrojne slovačke vojvođanske inteligencije je mnogostruk: povećati interesovanje naroda za obrazovanjem dece, obezbediti nedostajući učiteljski kadar i izdejstvovati povoljnije zakone prilikom uvođenja nastave državnog jezika u slovačke narodne škole. Cilj našeg rada je kroz analizu arhivske građe o osnovnoj školi u Kisaču i tadašnje štampe vojvođanskih Slovaka ukazati na uzajamnu srpskoslovačku saradnju u rešavanju školskih pitanja. U radu se razmatra i problem nedostatka učiteljskog kadra u slovačkim školama u Vojvodini koji je rešavan zapošljavanjem srpskih učitelja.

Ključne reči: srpsko-slovačke kulturne veze, osnovna škola sa slovačkim nastavnim jezikom, Kisač, 1919. g.-1929. g.

After the World War I and establishment of the new country, the Kingdom of Serbs, Croatians and Slovenians, schools become state schools and the teachers state officials. Even though the law demands that the teaching in each school is performed in the language native to the students attending, the law also obligates the teaching of some subjects in the state language. The task of the small group of Slovak Vojvodinian intelligence is manifold: increasing peoples' interest in schooling their children, providing for the insufficient teaching cadre, and acquiring more favourable laws when implementing the teaching of state language in the Slovak native schools. The goal of our work is to, through analysis of archival material about the grammar school in Kysač and the concurrent press of the Vojvodinian Slovaks, demonstrate the mutual collaboration of Serbs and Slovaks in solving school issues. We are particularly concerned with the problem of the shortage of teaching cadre in Slovak schools in Vojvodina, which was solved by employing of Serbian teachers.

Keywords: Serbian-Slovak cultural connections, grammar school in Slovak language, Kysač, year 1919-1929.

Prvi Slovaci su se u vreme terezijanske kolonizacije doselili u Kisač 1773. godine, gde je već živelo srpsko stanovništvo. ${ }^{1}$ Tada počinje zajednički život i uzajamna

\footnotetext{
* Rad je nastao u okviru projekta Diskursi manjinskih jezika, književnosti i kulture u jugoistočnoj i srednjoj Evropi (178017), koji finansira Ministarstvo prosvete, nauke i tehnološkog razvoja Republike Srbije.

${ }^{1}$ Stanovnici Kisača, 19 starosedelaca Srba, potpisali su ugovor sa Arsenijem Čarnojevićem kao vlasnikom Futoškog vlastelinstva 17. novembra 1758. godine (Ramač, 2010: 145). Prema urbarijalnom popisu Kisača iz 1772. godine, godinu dana pre dolaska prvog Slovaka u Kisač, u selu je bilo 107 domaćinstava, pretežno Srba. (OL, E szekció 156 - a. - Fasc. 158. - No. 024). Sa Futoškog vlastelinstva (iz Rumenke, Gložana i Kisača) je 1774. g. pobeglo 79 podanika Srba, tako da je u Kisaču ostalo svega 20 srpskih kuća. Nakon Prvog svetskog rata i nove agrarne reforme 1920. g. počinje intenzivna kolonizacija solunskih dobrovoljaca iz oblasti Hercegovine i Like. U blizini Kisača nastaje
} 
saradnja Srba i Slovaka u Kisaču, koja je između dva rata, pogotovo u oblasti osnovnog obrazovanja, bila plodna i obostrano korisna. Slovačke škole u Južnoj Ugarskoj (na teritoriji današnje Vojvodine) su bile istovetne sa slovačkim školama u Severnoj Ugarskoj (na teritoriji današnje Slovačke), odakle su, po pravilu, dolazili i učitelji na Donju zemlju (Južnu Ugarsku). I pored neprekidnih nastojanja vlasti da se škole mađarizuju, pogotovo krajem 19. i početkom 20. veka, jezik nastave u konfesionalnim školama je ostao slovački. Škole su od svog osnivanja imale crkveni karakter uz obavezan državni nadzor. Prema Andriji Ognjanoviću 1773. g. pominje se srpska škola u Kisaču a evangelističko-slovačka 1785. g. (195?: 105).

Vojvodina je sve do 1918. g. bila u okviru Habsburške monarhije, kada je nakon završetka Prvog svetskog rata Velika narodna skupština u Novom Sadu proglasila ujedinjenje Vojvodine sa Srbijom, a prvog decembra 1918. g. proglašeno je stvaranje Kraljevine Srba, Hrvata i Slovenaca. Slovaci u Vojvodini su jasno izrazili svoju lojalnost novoformiranoj državi, jer su u njoj videli spas od nasilne mađarizacije i asimilacije (Gubová Červená 2015: 38).

U oblasti školstva bile su učinjene korenite promene. Uredbom Ministarstva prosvete br. 13000/1919 škole su trebale da postanu državne, a učitelji od 1. XII 1919. g. državni činovnici (Národná jednota ${ }^{2}$ 1920/9, 3). Ova uredba nije istovremeno sprovedena u svim školama iz administrativnih razloga, već je to trebalo da bude učinjeno do kraja školske 1920/21. g. (Náš život³ 1933/1, 43).

Prvo nastavničko veće slovačkog državnog učiteljskog kolektiva u Kisaču je održano 2. IX 1921. g. U drugoj tački zapisnika nastavničkog veća Zápisnica školských porád 1904-1921 se navodi da zvanično imenovanje za državne učitelje dana 1. IV 1921. g. kolektiv prihvata sa zadovoljstvom (AOŠK). Slovaci su podržavljenje škole smatrali olakšavajućom okolnošću, jer su ,slovački učitelji u bratskoj vezi sa jugoslovenskim učiteljima“" imali obezbeđen status (za koji su do tada morali da se bore), a platom i rangom su spadali među državne činovnike (NŽ 1933/3-4, 71). Osim toga, neke siromašne crkvene opštine su, u teškim ekonomskim prilikama sa ogromnim poteškoćama izdržavale škole i učitelje (NJ 1920/9, 3). Rad i funkcionisanje slovačkih škola više nisu bili u kompetenciji slovačke evangelističke crkve, a isto tako su i srpske škole prestale da budu pod patronatom pravoslavne crkve. U političkim opštinama je izvršeno spajanje svih škola u jednu pod imenom Državna osnovna škola (Šimunović-Bešlin 2007: 188).

Radivoj Miškov u Sumarnom inventaru sa beleškom o fondu navodi da je u Kisaču škola od 1920. do 1934. g. funkcionisala pod imenom Slovačka državna osnovna škola Kisač (IAGNS, F86). Nastava na slovačkom jeziku u Kisaču se odvijala u sedam zgrada, a nastava na državnom, srpskom jeziku se odvijala u zgradi parohije srpske pravoslavne crkve (Berédiová-Stupavská 2013: 287). Zbog porasta broja učenika i nedovoljnog broja učionica već u školskoj 1921/22. g. prešlo se sa celodnevne na poludnevnu nastavu.

dobrovoljačko naselje Tankosićevo sa 26 doseljenih dobrovoljačkih porodica. Kasnije je ovo naselje pripalo Kisaču (Stojaković, 2013: 271), a 1936. g. je ovde izgrađena škola sa dve učionice čiji prostor su kasnije koristila kako srpska, tako i slovačka odeljenja škole u Kisaču.

${ }^{2}$ Dalje: NJ.

${ }^{3}$ Dalje: NŽ. 
Prema Knjizi saopštenja 1925-1927 Slovačke državne osnovne škole u Kisaču, u školi su bili zaposleni učitelji, kako Slovaci, tako i Srbi: Oljga Babilon rođ. Garaj (Ol'ga Babylonová rođ. Garajová), Anđelka Baras (rođ. Malešević), Milica Dodić, Jelena Gerić, Jovan Jakšić, Novka Jakšić (rođ. Erdeljan), Maria Juranji rođ. Dobšinska (Mária Jurániová rođ. Dobšinská), Ljubica Kekić, Jan Kljinko (Ján Klinko), Natalija Lugovskaja, Jan Pavlov, Julka Pavlov rođ. Kovač (Julka Pavlovová rođ. Kováčová), Ivan Pereligin, Aurelia/Zlata Porubska rođ. Jesenska (Aurélia/Zlata Porubská rođ. Jesenská), Maria Rusnak (Mária Rusnáková), Gustav Smetana (Gustáv Smetana), Peter Šimkovic, Maria Hrubik rođ. Voda (Mária Hrubíková rođ. Vodová) (IAGNS, F86). Osim ovih učitelja, do 1929. g. su bili zaposleni i: Karolina Mesik udata Čerfel (Karolína Mesíková vydatá Čerfelová), G. Demiden, Leposava Milosavljević, Žarko Nikolić, Jan Eđedi (Ján Ededy), Elena Parnicka rođ. Bodicka (Elena Párnická rođ. Bodická), Emil Klobušicki (Emil Klobušický), Milan Tutorov (Berédiová-Stupavská 2013: 291).

Za vreme Slovačkih narodnih svečanosti u Petrovcu 1925. g. održan je skup slovačkih učitelja. Jan Čajak, upravnik škole u Petrovcu, smatra da je greška, ali ne i krivica vlade što u slovačke škole šalje učitelje koji nisu slovačke nacionalnosti, jer ona samo popunjava prazna učiteljska mesta. Rešenje problema vidi u boljoj saradnji i komunikaciji između prosvetnih organizacija Slovaka i ministarstva prosvete (NJ 1925/34, 2). Aktivnosti po ovom pitanju su se intenzivirale 1928. g., neposredno pre donošenja novog zakona o narodnoj školi 1929. g. Na konferenciji slovačkih vojvođanskih učitelja održanoj u Kisaču (NJ 1928/2, 1) tekst rezolucije koja se bavi pitanjima nedostatka učiteljskog kadra u slovačkim školama sačinio je Peter Šimkovic, učitelj iz Kisača (NJ 1928/3, 2).

Školske 1927/28. g. je u školama na slovačkom nastavnom jeziku u Vojvodini radilo 110 učitelja, od čega 70 slovačke a 40 srpske nacionalnosti (NJ 1928/8, 1) - u Kisaču je u približnoj srazmeri bio broj slovačkih i srpskih učitelja , 7 : 3. Deset godina nakon stvaranja nove države broj slovačkih učitelja je pao sa 87 na 70, a stvaranje slovačkog učiteljskog podmlatka je zavisilo pre svega od dobre volje državne prosvetne vlasti (NJ 1928/9, 3). Učitelji srpske nacionalnosti su i dalje popunjavali učiteljska mesta u slovačkim školama, jer su ona ostala upražnjena nakon povratka određenog broja dotadašnjih učitelja u Čehoslovačku (NJ 1920/46, 1). Osim toga, novi zakon je predvideo manji broj učenika u odeljenju (NJ 1928/3, 3), što je povećalo potrebu za ionako nedovoljnim brojem učitelja slovačke nacionalnosti.

Zahvaljujući angažovanju Čehoslovačkog saveza, njenom sekretaru Karolu Lilgeu i prijateljima Slovaka iz redova srpske inteligencije (dr. Ivan Ribar i dr. Slavko Šećerov) (NJ 1928/40, 4) Ministarstvo prosvete je 10. VI 1928. g. odlukom pod brojem ONBr. 45.752, dozvolilo kurs za slovačke učitelje koji je počeo 11. VII, a završio se 28. VIII 1928. g. Ciljna grupa su bili maturanti petrovačke gimnazije koji su se za vreme raspusta o vlastitom trošku grupno prijavili na kurs. Pošto je ministarstvo odugovlačilo sa njihovom promocijom, nastavljeno je sa praksom imenovanja srpskih učitelja u slovačka odeljenja (NJ 1929/20, 1).

Iako je ministarstvo odobrilo kurs za slovačke učitelje, a dokaz o položenom kursu je imao pečat državne institucije, kao i potpis posebnog poverenika ministarstva prosvete - tekst zakona o narodnim školama nije predvideo takvu mogućnost, tako da je problem učiteljskog kadra u slovačkim školama i dalje ostao nerešen (NJ 1931/54, 3). Na kursu je osim 36 maturanata Slovačke realne gimnazije u Petrovcu (osnova- 
na 1919. g.), učestvovalo i osam učitelja sa ciljem usavršavanja slovačkog jezika (NJ 1928/36, 2). Među njima je bila i učiteljica Anđelka Baras srpske nacionalnosti, zaposlena u Kisaču od 1925. g., a koja je tek kasnije, od 1934. do 1939. g., radila u slovačkim odeljenjima četvrtog razreda u Kisaču. Nakon toga je prešla u Novi Sad. ${ }^{4}$ I pre toga su u Kisaču u slovačkim odeljenjima radili učitelji drugih nacionalnosti. U prvoj tački zapisnika nastavničkog veća (Zápisnica školských porád 1904-1921) održanog 2. IX 1921. g. se navodi da je Milica Dodić prvi put prisutna na zajedničkom nastavničkom veću slovačkih i srpskih učitelja u okviru sada već objedinjene državne škole u Kisaču. Pošto je u slovačkoj školi bilo 709 učenika a samo 6 nastavnika slovačke nacionalnosti (tri učiteljska mesta su bila upravo otvorena, a od prošle školske godine je takođe ostalo nepopunjeno jedno učiteljsko mesto), sama je predlagala da bi rado preuzela 20 slovačkih učenika u srpsku školu koju je tada pohađao 21 učenik (AOŠK). M. Dodić je u svom radnom dosijeu imala zabeleženo znanje slovačkog jezika, ali je postavljena od strane Srpske pravoslavne crkvene opštine u Kisaču i od 1909. do 1925/26. šk. g. je radila samo u srpskim odeljenjima, nakon čega je premeštena u Srbobran. ${ }^{5}$ Marija Adamović je rođena u Istri, bila je jugoslovenske narodnosti, katoličke veroispovesti i sa dobrim znanjem slovačkog jezika. Ne može se sa sigurnošću tvrditi da je njeno premeštanje imalo veze sa rezolucijom narodnog saveta Slovaka donešenom na Slovačkim narodnim svečanostima 1926. g., prema kojoj se osim poznavanja slovačkog jezika u slovačkim školama traži i postavljanje učitelja iste vere (NJ 1926/33, 1), što je za Kisač bila evangelistička veroispovest. Evidentno je, da je M. Adamović u Kisaču radila od 1923. do 1927. g. kao stalna učiteljica u odeljenju sa slovačkim nastavnim jezikom, nakon čega je premeštena u Rumenku. ${ }^{6}$

I odeljenja na državnom jeziku su usled razmeštanja srpskih učitelja u slovačka odeljenja trpela nedostatkom kadrova. Učitelj ruske nacionalnosti Ivan Pereligin (koji je vladao državnim jezikom sa osetnim naglaskom; ruski izbeglica potporučnik koji je u Rusiji završio učiteljsku školu, Vojnu akademiju u Moskvi i Bogoslovskoučiteljsku školu u Prizrenu), u državnom odeljenju škole u Kisaču je radio od 1925/26. do 1929. g. kada je premešten u Gribovac. ${ }^{7}$

Ideja vodilja slovačkih prosvetnih radnika bila je slovenska uzajamnost koju je potencirao najpre Čehoslovački savez u Kraljevini SHS (1921-1932) čiju ulogu preuzima novoosnovana Matica slovačka u Jugoslaviji 1932. g. Tako je na kongresu čehoslovačkih učitelja 2. II 1928. g. u Staroj Pazovi objavljena rezolucija da su učitelji čehoslovačkih škola spremni na saradnju i na zbližavanje sa jugoslovenskim učiteljima (NJ 1928/19, 2). Slovački učitelji u Kisaču su bili aktivni učesnici skupova, konferencija i kongresa slovačkih učitelja u Vojvodini i dosledno su primenjivali donesene odluke.

Član 45 Zakona o narodnim školama iz 1929. g. dozvoljavao je da manjinske škole sa najmanje dva odeljenja mogu imati svog upravnika (Ededy 1939: 193194), ali on nije bitnije uticao na ustaljenu praksu u ovoj školi, pa su se i pre i posle

\footnotetext{
${ }^{4}$ Vojvođanski arhiv F 126 IV (personalni dosije Anđelka Baras)

${ }^{5}$ Vojvođanski arhiv F 126 IV (personalni dosije Milica Dodić)

${ }^{6}$ Vojvođanski arhiv F 126 IV (personalni dosije Marija Adamović)

${ }^{7}$ Vojvođanski arhiv F 126 IV (personalni dosije Ivan Pereligin)
} 
donošenja ovog zakona upravnici škole u Kisaču birali iz redova kako Slovaka, tako i Srba: Gustav Smetana (1923-1925), Jan Kljinko (1925-1929), Jovan Jakšić (1929-1930).

Takođe su se i članovi školskog odbora birali srazmerno iz redova Srba i Slovaka (Zapisnik skupštine opštinskog predsedništva 1910-1927, str. 136; Opština Kisač, IAGNS).

U školi su se obeležavali kako srpski, tako i slovački državni i verski praznici (Knjiga saopštenja 1925-1927, 30. 11. 1926, 12.5. 1926, 3.5. 1925, 7.1. 1927, 1.2. 1927; IAGNS).

U ovom periodu su konstantno bila prisutna razočarenja slovačkih učitelja u vezi stava srpskih prosvetnih vlasti prema njima. Slovački učitelji su morali da polažu ispite iz nacionalnih predmeta, a zatim se o njihovom zapošljavanju odlučivalo u Beogradu. Čak je bilo reči i o premeštanju slovačkih učitelja u Makedoniju, ali nisu poznati takvi slučajevi (Gubová Červená 2015: 116). Slovaci su se u ovih deset godina borili za svoja prava u novoj državi posredstvom slovačkih političkih organizacija, prosvetnih institucija ali i pripadnika slovačke inteligencije manje-više bezuspešno. Ponavljali su svoje zahteve u vezi zapošljavanja slovačkih učitelja u slovačke škole, u vezi statusa i dovoljnog broja časova iz nastavnih predmeta slovački jezik i istorija. Državne institucije nisu reagovale, što nije začuđujuće s obzirom na činjenicu da je država bila nestabilna, a od svog osnivanja do 1929. g. (kada je kralj Aleksandar Karađorđević proglasio diktaturu i preimenovao KSHS u Kraljevina Jugoslavija) imenovano je čak 25 vlada (Gubová Červená 2015: 225, 233, 243, 265, 311).

Dugotrajno haotično stanje u državnim i prosvetnim institucijama nije bitnije uticalo na započetu dobru saradnju slovačkih i srpskih učitelja u Kisaču i na taj način je omogućeno primerno funkcionisanje mesne osnovne škole u periodu postojanja Kraljevine Srba, Hrvata i Slovenaca.

\section{Citirana literatura}

Berediová-Stupavská, L’udmila: Dejiny školy v Kysáči. In: Kysáć 1773 -2013 (Vladimír Valentík, ed.). Báčsky Petrovec: SVC, Matica slovenská v Srbsku; Kysáč Rada Miestneho spoločenstva, 2013.

Gubová Červená, Gabriela: Slováci v Král'ovstve Srbov, Chorvátov a Slovincov 19181929. Báčsky Petrovec: SVC, Nový Sad: Ústav pre kultúru vojvodinských Slovákov, 2015.

Ededy, Ján: Prítomný stav slovenského l’udového školstva v Juhoslávii. In: Náš život, 1939/3-4.

Ognjanović, Andrija: Vojvođanske narodne osnovne škole i njihovi učitelji od 1573 do 1774. godine. Novi Sad: Matica srpska, 195 ?.

Шимуновић-Бешлин, Биљана: Просветна политика у Дунавској бановини (19291941). Нови Сад: Филозофски факултет, Одсек за историју, 2007. 


\title{
Izvori
}

Istorijski časopisi:

Náš život (1933-1941; 1946-1947)

Národná jednota (1920-1941)

Arhivska građa:

Arhiv Vojvodine Novi Sad, fond 126 IV (AVNS)

Istorijski arhiv Grada Novog Sada, fond 86: Osnovna škola sa slovačkim nastavnim jezikom Kisač, (IAGNS)

Arhiv Osnovne škole „Ljudovit Štur“ Kisač: Zápisnica školských porád 1904-1921 (AOŠK)

\section{Daniela Marčok}

\section{EDUCATION IN THE CONTEXT OF SLOVAK-SERBIAN RELATIONS IN THE SLOVAK GRAMMAR SCHOOL IN KYSAC IN THE KINGDOM OF SERBS, CROATS AND SLOVENES}

\begin{abstract}
Summary
After the World War I and creation of the new country (The Kingdom of Serbs, Croatians and Slovenians) Slovak confessional schools become state-owned. In the political municipalities all schools were merged into one, called the State Grammar School, with the students of different nationalities being legally allowed to attend the school in their native language. In Kysač, Slovak and Serb schools were unified and from 1920 to 1934 worked under the name Slovak State Grammar School Kysač. Because it was no longer possible to hire teachers from Czechoslovakia, and the number of students per classroom was officially reduced, the demand for Slovak teachers increased. The authorities were forced to hire teachers of Serb nationality to teach in Slovak schools (in classes administered in the Slovak language) and Kysač was not an exception. The guiding idea of Slovak educational workers was Slavic reciprocity, fostered first by the Czechoslovak alliance (1921-1932) and later by the Matica slovačka in Jugoslavia, established in 1932. Slovak teachers in Kysač were actively involved in these organizations and contributed to the solving of school issues. Interested Serbian teachers were enabled to perform teaching in Slovak language in schools in Novi Sad and also in the Kysač school. It was an established practice in this school to also choose school managers from the ranks of the Serb and Slovak teachers. Good mutual cooperation between the Slovak and Serb teachers in Kysač, facilitated the proper functioning of the communal grammar school in the period of existence of the Kingdom of Serbs, Croats and Slovenes.

Keywords: Serb-Slovak cultural connections, grammar school in Slovak language, Kysač, year 1919-1929.
\end{abstract}

